\section{One step backwards for hepatitis B testing?}

The use of enzyme linked immunosorbent assays (ELISA) for hepatitis B surface antigen $(\mathrm{HBsAg})$ detection is routine in many virology laboratories. Recently, some of these assays have been modified by the introduction of monoclonal antibodies and a combination of incubation steps. We report here some preliminary results that indicate a potential problem with such an assay for routine use in this department and other laboratories.

A serum sample from a known $\mathrm{HBsAg}$ carrier was tested by the one step ELISA of Abbott Laboratories Ltd, according to their assay procedures. Briefly, the patient's serum was mixed with mouse monoclonal anti-HBsAg peroxidase conjugate, and a bead coated with mouse monoclonal antiHBsAg was added. After incubation overnight (range 12-20 hours) at room temperature (range $15-30^{\circ} \mathrm{C}$ ) the bead was washed, enzyme substrate added, and the reaction stopped after 30 minutes. Positive ( 9 $\mathrm{SD} 2 \mathrm{ng} / \mathrm{ml} \mathrm{HBsAg}$ ), negative and substrate controls were included. The absorbance of the sample and controls were read on Abbott's Quantum II spectrophotometer.

The absorbance value for the positive control was $>2$ and negative control 0.017 , which gave a cut off for a positive sample of 0.067 (negative control value plus 0.05 units). The test sample had a value of 1.575 absorbance units, indicating that it was positive for HBsAg but at low level. In our experience, a serum sample giving such a low absorbance by ELISA would be negative when tested by the less sensitive method of reverse passive haemagglutination (Wellcome Diagnostics Ltd). This particular sample, however, gave an HBsAg titre of 32000 by this test showing that the HBsAg was present at a high level. To investigate further the test sample was diluted $7 / 1000$ and retested by a one step ELISA as before. The sample was also tested undiluted by the two step procedure using the same monoclonal ELISA. In the latter case the sample and bead were incubated together and after washing enzyme conjugate was added. In both cases the absorbance values were $>2$ units. A further three clinical serum samples of known high HBsAg titre were tested by the one step ELISA, both undiluted and at a dilution of $7 / 1000$. Although the absorbance values were $>2$ units in the three pairs of samples, dilution of the reaction products showed that the diluted sera had given twice the absorbance of their undiluted partners.

The presence of high titre $\mathrm{HBsAg}$ may therefore result in a prozone-like phenomenon in the one step ELISA, as predilution of the test serum or use of the two step ELISA reduces this interference. Although it is unlikely that a clinical sample would have sufficient HBsAg to push the absorbance value below the cut off, low absorbance values should not be interpreted as representing low $\mathrm{HBsAg}$ titres. $\mathrm{HBsAg}$ present in excess may bind to both the solid phase (bead) and enzyme label to such an extent that crosslinking between them is reduced. We are collaborating with the manufacturers of this kit to investigate these initial observations further, and full details will be published.

$$
\begin{array}{r}
\text { SJ RICE } \\
\text { Department of Virology, } \\
\text { Royal Postgraduate Medical School, } \\
\text { London W12 } 0 \mathrm{HS} .
\end{array}
$$

\section{Use of des- $\gamma$-carboxyprothrombin in retro- spective diagnosis of hidden intoxication of anticoagulants}

The des- $\gamma$-carboxy-prothrombin (DCP) is synthesised in hepatocytes, where it is carboxylated by a vitamin $K$ dependent enzyme. ${ }^{1}$ Vitamin $\mathrm{K}$ deficiency or the intake of oral anticoagulant therapy (OAT) inhibit the vitamin $\mathrm{K}$ dependent carboxylase. An increase in DCP has also been found in $67 \%$ of the cases of hepatocellular carcinoma. ${ }^{2}$ Recently, a new assay for DCP was described, ${ }^{3}$ the results of which are expressed in milliunits $(\mathrm{mU})$ per $\mathrm{ml}$. After studying the plasma of numerous blood donors the upper limit of normal DCP was found to be $15 \mathrm{mU} / \mathrm{ml}$. The concentration of DCP during OAT intake (with a prothrombin time at 25 to $35 \%$ ) was 200 to 300 $\mathrm{mU} / \mathrm{ml}$. DCP values returned to their initial concentrations three weeks after OAT had been stopped (unpublished data).

Four days after a diffuse bleeding syndrome a 60 year old man was brought to the hospital by his family. He did not admit taking medication. Tests of haemostatic function (prothrombin time, PTT, fibrinogen rate, thrombin time, platelet count, bleeding time) were normal on the day of admission. DCP assay showed high rates which then progressively decreased $(180 \mathrm{mU} / \mathrm{ml}$ on day 1 and $39 \mathrm{mU} / \mathrm{ml}$ on day 7). The interpretation of these values established that the highest value corresponded to the day the bleeding syndrome began. Afterwards the patient admitted that he had had OAT (acenocoumarol).

When the drug is stopped and the prothrombin time has returned to normal, an increased and then progressively decreasing DCP concentration permits a retrospective diagnosis three weeks after a hidden intake of OAT.

J-J LEFRERE

DANIELLE GOZIN

Centre National de Transfusion Sanguine,

6 Rue Cabanel, 75015 , Paris, France.

References

1 Nelsestuen GL, Zytkovicz TH, Howard JB The mode of action of vitamin $\mathrm{K}$ : identification of gamma-carboxyglutamic acid as a component or prothrombin. $J$ Biol Chem 1974;249:6347-50.

2 Liebman HA, Furie BC, Tong MJ, et al. Desgamma (abnormal) prothrombin as a serum marker of primary hepatocellular carcinoma. N Engl J Med 1984;310:1427-31.

3 Soulier JP, Gozin D, Lefrère JJ. Nouvelle méthode de dosage fonctionnel de la dégamma-carboxyprothrombin à l'aide de staphylocoagulase. Application au diagnostic des carcinomes hépatocellulaires. Presse Med 1985; 14:2049-52.

\section{Book reviews}

Nuclear Submicroscopy. Vol 12. Methods and Achievements in Experimental Pathology. Eds G Jasmin, R Simard. (Pp 300; £89-70.) Karger. 1986. ISBN 3-8055-4137-6.

This volume presents a series of studies and reviews on the structure and organisation of the nucleus. The computer reconstruction of nuclear detail from serial sections is of great interest and there are excellent chapters on the organisation of chromatin on the nuclear matrix and nuclear changes in viral replication. A chapter on autoantibodies in rheumatic diseases seems strangely out of place.

Pathologists spend a great deal of time studying the nucleus, yet in a very superficial way. This book points ways to the future for a better understanding of nuclear structure and function. It is likely to be of little immediate use to the diagnostic pathologist but a copy in the departmental library of a teaching department would be very stimulating for those young pathologists looking for new areas of advancement.

G SLAVIN 